\title{
OPINION AGREEMENT ANALYSIS OF SUPREME COURT JUSTICES: A METHODOLOGICAL NOTE
}

\author{
C. Jeddy LeVar \\ (Henderson State University)
}

The purpose of this paper is to explain the uses of opinion agreement analysis in studying appellate courts and provide examples of those uses with U.S. Supreme Court justices. This method is a relatively new approach, whose potential for expanding our knowledge about judicial behavior is just beginning to be tapped.

Opinion agreement analysis differs from the traditional voting bloc analysis and Guttman scaling. Opinion agreement analysis is based on who joins whose opinions, while voting bloc analysis and scaling use the judges' votes as the raw data. Voting bloc analysis is used to identify the extent to which judges vote together. Scaling has been useful in identifying the degree to which judges support such values as civil liberties, economic liberalism, and federalism (Heck, Schubert). Voting bloc analysis and scaling thus complement each other. Bloc analysis identifies who votes with whom, while scaling is widely used to suggest that the voting bloc's exist because of shared attitudes or ideology (Schubert 1974; LeVar 1977).

Using scaling to support the theory that judges' votes reflect their attitudes, though, is a circular argument. Since scaling is based on votes, the argument turns out to be one in which votes are used to explain votes!

Opinion agreement offers one solution to the problem. Opinion agreement is a simple indicator of how much judges go along with each others' ideas. Since it measures the extent to which judges think alike, it may provide an independent explanation of voting agreement.

The thrust of this paper will be to show how opinion agreement can be used to:

1. Identify attitude blocs and compare them to voting blocs;

2. rank the justices based on the extent to which their attitudes are in the mainstream of court's thought;

3. determine who in the bloc is the driving force, i.e., whose opinions most unify the bloc or in other words who is the most influential member of the bloc; and 
4. rank the justices in terms of their overall influence on each other in civil liberties cases.

The literature on opinion agreement analysis is limited and focuses on using the technique to explain influence or "leadership" on courts. The first published article embodying it traced the lines of influence or "leadership" among the justices of the U.S. Supreme Court (LeVar 1977). In that study of the Nixon Court, the author used both traditional voting bloc and the new opinion agreement analyses. Voting blocs in the issue areas of civil liberties, economic regulation, judicial activism, and nationalism were identified. Then, using opinion agreement, Brennan was found to be the leader of the nationalist, activist, liberal economic regulation, and liberal civil liberties blocs. Rehnquist was reported to be the leader of the conservative civil liberties bloc. Blackmun was the leader of the statesrights bloc. Powell turned out to be the leader of two blocs: conservative economic regulation bloc and the judicial self-restraint bloc. Burger turned out to be relatively uninfluential as a bloc leader (LeVar 1977).

Perry (1982) used weighted indicators of deference in his study of Burger's overall influence from 1976-79. His standards were (1) full deference (when one justice joins another's opinion exclusively and does not author one himself), (2) substantial deference (when a justice writes a joint concurrence with the court or joins a justice's opinion but also the opinion of another justice), and(3) partial deference (joining parts of an opinion or joining concurrences with reservations). As with LeVar, Perry found Burger's influence relatively low. However, he did argue that Burger exercised "proxy influence" to a significant extent through Rehnquist.

Spaeth and Altfeld (1985) studied influence on the Supreme Court from 1969-80, using opinion agreement analysis. They found that seniority had little affect on justices' influence. They concluded that influence was limited largely to justices who have similar ideologies. On a more personal level, in the early Burger Court years Brennan and Douglas were said to have been influenced by twice as many colleagues as they influenced. Powell was said to have done more influencing than any of his ideological associates.

LeVar (1988) combined quantitative and textual analysis to study overall leadership on the Supreme Court during the Burger-O'Conner years. The study was limited to civil liberties cases. Powell was identified as the justice who had the most influence in written opinions. He exercised this leadership primarily in discrimination type of cases. When 


\section{Jeddy LeVar}

functioning as a leader in this type of cases, Powell defended traditional practices (such as paying women less retirement benefits than men and limiting male intrusion into nursing school) and states rights. He also took a restraintist approach to the exercise of judicial power, using rationality analysis rather than strict scrutiny and requiring the exhaustion of administrative remedies before judicial appeal.

\section{Methodology}

In this analysis of opinion agreement among Supreme Court justices, decisions from October 1981 through June 1986 will be used. During this five year period there were no personnel changes on the Court, which makes the analysis cleaner.

Some writers prefer to confine their analysis to unassigned opinions, when they are studying influence or "leadership" within the court. They argue that including assigned opinions introduces an element of pressure in that some may join assigned opinions to maintain coalitions (see Spaeth and Altfeld). The results one gets, of course, are affected by the method used. For example, if only unassigned opinions were used here Powell would displace Burger as the overall leader.

I opt to include all opinions--assigned and unassigned--for two reasons: (1) coalitions may be maintained by voting with the majority while writing concurrences, thus minimizing any pressure to join an opinion, and (2) leaving out assigned opinions systematically eliminates instances when a justice is exercising influence to build his largest number of followers. Thus, omitting the assigned opinions could mask the Chief Justice's influence, even though at times he assigns himself some of the easier opinions.

I also include opinions in unanimous as well as nonunanimous decisions. Nonunanimous decisions are usually the basis for Guttman scaling, since unanimous votes reveal nothing about how judges differ. In opinion agreement analysis, though, the situation is different: In many unanimous decisions separate opinions are written, thus revealing how judges differ.

The study will be limited to three types of civil liberties cases: first amendment, police treatment (search \& seizure and interrogation), and discrimination. These three issue areas are representative of the three kinds of rights guaranteed in the Constitution: (1) substantive (first amendment), (2) procedural (police treatment), and (3) equality (discrimination). 
There were no major problems in classifying cases into the three areas. When more than one area was involved in a case, the case was put into the category used by the majority as the principal basis for its decision. There were a few judgment calls, but not enough to change the resulting patterns.

A one sentence statement that a justice concurred with or dissented from a vote or opinion was not treated as an opinion. "I agree or disagree with the Court's opinion" is not a call for support, and if joined by a colleague produces a situation in which it is impossible to tell who influenced whom.

Percentages will be used to measure the extent to which justices join each others' opinions. Opinion agreement scores will be defined as the percent of times a justice agrees with a colleague when the colleague writes opinions.

\section{Attitude Blocs}

As already indicated, the use of opinion agreement scores to identify attitude blocs is conceptually different from the process of identifying voting blocs. Voting blocs are based on how justices vote. Attitude blocs, on the other hand, are based on opinion agreement and directly measure shared attitudes. Thus, when an attitude bloc exists, that is direct evidence that the members of the bloc share similar attitudes. This interpretation is buttressed by the freedom justices have to write separate opinions and choose to join or not join each others' opinions.

Determining attitude blocs is a bit more complicated than identifying voting blocs. When several justices vote together frequently, that alone will be sufficient to call them a voting bloc. Opinion agreement, though, has two dimensions. For example, when Brennan wrote opinions, Burger joined only three percent of them; however, when Burger wrote opinions, Brennan joined thirty percent of them. Before an attitude bloc may be said to exist, both dimensions of the interagreement must be taken into consideration.

Sprague's criterion has been used to identify voting blocs. Sprague's criterion allows justices to be considered a voting bloc when their interagreement scores exceed half the distance between 100 percent and the average court cohesion. Because so many separate opinions were written which were not joined by any colleague and because our analysis here has to be two dimensional, Sprague's criterion proved to be too demanding.

In this paper an attitude bloc will be said to exist when the agreement scores on both dimensions exceed one-third the distance between 100 
percent and the average opinion agreement score of the Court. The formula is: $(100$-av. agreement score $) / 3+$ av. agreement score $=$ criterion for inclusion in a bloc.

During the period in this study, the average opinion agreement score of the Court was 29.6 percent. In order for an attitude bloc to exist, justices would have to agree with each other at least 53.1 percent of the time, regardless of who wrote the opinions. Using that criterion, two attitude blocs emerged: (1) Brennan and Marshall and (2) Rehnquist and Burger. When Brennan wrote opinions, Marshall joined them 82 percent of the time, and when Marshall wrote opinions Brennan joined them 59 percent of the time. When Rehnquist wrote opinions, Burger joined them 65 percent of the time, and when Burger wrote opinions, Rehnquist joined them 64 percent of the time. All of the opinion agreement scores are listed in Table 1.

Table 1. Opinion Agreement Scores of Supreme Court Justices

\begin{tabular}{|c|c|c|c|c|c|c|c|c|c|}
\hline \multirow[t]{2}{*}{ Joiners } & \multicolumn{9}{|c|}{ Writers } \\
\hline & Bre & Mar & Bla & Ste & Pow & Whi & $\underline{\mathrm{Oco}}$ & $\underline{\text { Reh }}$ & Bur \\
\hline Brennan & -- & 59 & 39 & 34 & 23 & 23 & 17 & 15 & 30 \\
\hline Marshall & 82 & -- & 39 & 30 & 15 & 21 & 19 & 15 & 28 \\
\hline Blackmun & 39 & 34 & -- & 24 & 29 & 26 & 29 & 28 & 47 \\
\hline Stevens & 35 & 34 & 23 & -- & 23 & 24 & 25 & 26 & 32 \\
\hline Powell & 24 & 11 & 7 & 16 & -- & 33 & 29 & 48 & 60 \\
\hline White & 17 & 18 & 13 & 16 & 23 & -- & 21 & 44 & 57 \\
\hline O'Connor & 14 & 11 & 15 & 17 & 46 & 39 & -- & 56 & 64 \\
\hline Rehnquist & 2 & 7 & 5 & 15 & 52 & 46 & 40 & -- & 64 \\
\hline Burger & 3 & 11 & 5 & 16 & 48 & 47 & 39 & 65 & -- \\
\hline $\mathrm{n}=$ & 66 & 44 & 39 & 76 & 52 & 66 & 52 & 54 & 47 \\
\hline
\end{tabular}

At this point it might be asked how a voting bloc would differ from an attitude bloc, using the same cases. When Sprague's criterion was used to identify voting blocs using the same cases, two voting blocs emerged: Brennan-Marshall and Burger-Rehnquist-O'Connor, with Powell as a fringe member. 
The traditional voting bloc analysis correctly ties together the voting similarity; however, it misses the subtle attitude differences measured by opinion agreement analysis since justices may vote together but have different reasons for doing so. When used together, the two techniques complement each other. In this case it may be said that the BrennanMarshall bloc is highly cohesive in both voting and attitude dimensions. On the other hand, the Burger-Rehnquist-O'Connor-Powell (fringe) voting bloc consists of justices with more disparate attitudes, since only Burger and Rehnquist are included in the attitude bloc.

The challenge which next arises is to determine whether these two attitude blocs are liberal or conservative. The usual approach to determine the substance of judges' attitudes is to rely on Guttman scaling. However, as already mentioned, that would involve using votes to determine the attitudes, which in turn are used to explain the votes!

The way out of this circular reasoning is to utilize traditional textual analysis of opinions. From reading their opinions it became clear that the Brennan-Marshall bloc shared a liberal attitude, while the BurgerRehnquist bloc shared a conservative attitude. (A liberal attitude was defined as one which supported the expansion of individual rights, while a conservative attitude was deemed to be one which opposed the expansion of such rights.)

\section{Bloc Leaders}

After identifying the attitude blocs, opinion agreement scores can be used to determine which member of each of the blocs is the driving force, or in other words who is influencing whom, holding the bloc together. One technique for doing this is to look at the average support score of each bloc member. (The average support score of a justice is the average percent of times other bloc members join that justice's opinions.) In this study each bloc contains only two members, so no average needs to be figured. The support scores can be taken directly from Table 1.

The support scores for the bloc members are:

$\begin{array}{ll}\text { Brennan } & 82 \\ \text { Marshall } & 59 \\ \text { Rehnquist } & 65 \\ \text { Burger } & 64\end{array}$




\section{Jeddy LeVar}

Brennan turned out to be the more influential member of his bloc. There was no clear dominant member of the Rehnquist-Burger bloc.

\section{Overall Influence}

When judges are ranked on the basis of the average support scores they get from all other members of the court, the result is a rough indication of the extent to which judges influence each other in their written opinions. Table 2 reveals how the judges were ranked in this study.

Table 2. Overall Influence in Written Opinions

$\begin{array}{lc}\text { Justices' Rankings } & \text { Average Support Score } \\ \text { Burger } & 48 \\ \text { Rehnquist } & 37 \\ \text { Powell } & 32 \\ \text { White } & 32 \\ \text { O'Connor } & 27 \\ \text { Brennan } & 27 \\ \text { Marshall } & 23 \\ \text { Stevens } & 21 \\ \text { Blackmun } & 18\end{array}$

\section{Mainstream Attitudes}

There is yet another way to interpret the ranking of justices on the basis of their support scores as in Table 2. The rankings give rough estimates of the extent to which the justices' attitudes are in the mainstream of the court.

Justices with the higher rankings, such as Burger and Rehnquist, seem to be more in the court's mainstream of thought. Justices with the lower rankings, such as Stevens and Blackmun, would appear to be more out of that mainstream.

\section{Conclusion}

Aside from illustrating the diverse uses of opinion agreement analysis in conjunction with textual analysis, one implication of this study is 
that Burger's influence on the Court either increased in the later years of his term or was undetected by the earlier studies which used only unassigned opinions (see LeVar, 1988; and Spaeth and Altfeld).

The principal methodological conclusions are:

1. Opinion agreement analysis has the promise of being very useful in testing theories about judicial attitudes and behavior. Since it directly measures shared attitudes, it avoids the circularity trap when scaling to demonstrate the relationship between judicial attitudes and voting.

2. Opinion agreement analysis enables one to quantify influence. The usual approach to studying influence on the Supreme Court has been to interpret subjectively notes, memoranda, interview responses, journals, etc. (see Ulmer; Woodward and Armstrong). Without denigrating the subjective approach, opinion agreement analysis adds a quantitative element to the literature on judicial influence and leadership.

3. Determining which justices are in the mainstream of the Court's thought adds a new dimension to our understanding of the Supreme Court. Such a determination cannot be made cleanly with voting data--it requires some quantification of shared attitudes. Opinion agreement analysis provides such quantificaiton.

4. The procedure is not, however, without problems. For one, the test suggested by Sprague to determine voting blocs seems too restrictive to be used in determining attitude blocs. A subjective adjustment to the Sprague criterion was adopted. Another problem is whether to use all opinions or just the unassigned ones. Yet, the simplicity of the methodology and its direct tapping of attitudes provides much promise.

\section{References}

Heck, Edward V. 1988. "Civil Liberties Voting Patterns in the Burger Court, 1975-78." Western Political Quarterly, 34): 193-202.

LeVar, C. Jeddy. 1977. "The Nixon Court: A Study of Leadership." Western Political Quarterly, 30: 484-492.

LeVar, C. Jeddy. 1988. "Leadership on the U.S. Supreme Court: The Burger-O'Connor Years." Paper presented at the annual meeting of the Southwestern Political Science Association, March 23-26, 1988. 


\section{Jeddy LeVar}

Perry, R. Christopher. 1982. "Patterns of Intellectual Deference: Personal and Proxy Influence of Chief Justice Burger, 1976-79." Paper delivered at the arnual meeting of the Arkansas Political Science Association, February 26-27, 1982.

Schubert, Glendon. 1974. The Judicial Mind Revisited: Psychometric Analysis of Supreme Court Ideology. New York: Oxford University Press.

Spaeth, Harold J. and Altfeld, Michael F. 1985. "Influence Relationships Within the Suprme Court." Western Political Quarterly, 38: 70-83.

Ulmer, S. Sidney. 1971. "Earl Warren and the Brown Decision," The Journal of Politics 33 (August) 689-702.

Woodward, Bob and Armstrong, Scott. 1979. The Brethren. New York: Simon and Schuster, 1979. 